\title{
The Delivery of Personalised, Precision Medicines via Synthetic Proteins
}

\author{
Benedita Kaç Labbé Feron and Simon Clifford Wainwright Richardson* \\ Exogenix Laboratory, Faculty of Engineering and Science, University of Greenwich, Central Avenue, Chatham Mari- \\ time, Kent, ME4 4TB, UK
}

\begin{abstract}
Introduction: The design of advanced drug delivery systems based on synthetic and supramolecular chemistry has been very successful. Liposomal doxorubicin $\left(\right.$ Caelyx $\left.{ }^{\mathbb{Q}}\right)$, and liposomal daunorubicin (DaunoXome ${ }^{\mathbb{B}}$ ), estradiol topical emulsion $\left(\right.$ Estrasorb $^{\mathrm{TM}}$ ) as well as soluble or erodible polymer systems such as pegaspargase $\left(\right.$ Oncaspar $\left.{ }^{\circledR}\right)$ or goserelin acetate $\left(\right.$ Zoladex $\left.^{\circledR}\right)$ represent considerable achievements.
\end{abstract}

The Problem: As deliverables have evolved from low molecular weight drugs to biologics (currently representing approximately $30 \%$ of the market), so too have the demands made of advanced drug delivery technology. In parallel, the field of membrane trafficking (and endocytosis) has also matured. The trafficking of specific receptors i.e. material to be recycled or destroyed, as well as the trafficking of protein toxins has been well characterized. This, in conjunction with an ability to engineer synthetic, recombinant proteins provides several possibilities.

The Solution: The first is using recombinant proteins as drugs i.e. denileukin diftitox $\left(\right.$ Ontak $\left.^{\circledR}\right)$ or agalsidase beta $\left(\right.$ Fabrazyme $\left.^{\mathbb{B}}\right)$. The second is the opportunity to use protein toxin architecture to reach targets that are not normally accessible. This may be achieved by grafting regulatory domains from multiple species to form synthetic proteins, engineered to do multiple jobs. Examples include access to the nucleocytosolic compartment. Herein the use of synthetic proteins for drug delivery has been reviewed.

Keywords: Protein toxin, endomembrane, exosome, endocytosis, drug delivery, siRNA, antisense.

\section{INTRODUCTION}

The aim of this paper is to explore the use of protein architecture to mediate drug delivery, borrowing domains and motifs of known function to solve problems associated with drug bioavailability. There are currently more than 200 biopharmaceutical products on the market, representing a market of approximately $\$ 70-80$ billion (about $30 \%$ of all licensed marketed drugs) [1,2]. Unlike many drugs based upon small molecules, biopharmaceutics often requires advanced drug delivery technology to address three limitations associated with its use i.e. stability in biological fluids, immunogenicity and in vivo half-life [3]. In addition to the aforementioned limitations, target compartment accessibility is also a significant challenge. However, drugs based upon a molecule or supramolecular assembly that have evolved to reach normally inaccessible target compartments prove to be the exception [4]. This is pertinent to drug delivery as "third order", or organelle-specific targeting remains a significant challenge, which is exemplified by the problems associated with the delivery of nucleic acid based drugs [4]. Although

*Address correspondence to Dr Simon Richardson, Faculty of Engineering and Science, University of Greenwich, Central Avenue, Chatham, Kent, ME4 4TB UK. Tel +44-208-331-8207; E-mails: rs73@Greenwich.ac.uk there are numerous studies highlighting the compartmentalisation of cells as a barrier to third order targeting [4], perhaps the most compelling evidence is the everyday use of a variety of transfection systems in research laboratories across the world.

These transfection systems are diverse and include: Active Motif's Chariot reagent (for proteins) [5], the Nucleofection $^{\mathrm{TM}}$ (electroporation) systems sold by Lonza [6], the various combinations of cationic polymers and lipids (i.e. FuGene $6^{\circledR}$ (Roche) [6] or Lipofectamine 2000 (Invitrogen) [7]) and the Helios gene gun (BioRad) [8]. In vivo some success has been achieved using attenuated, replication deficient viruses as transfection vehicles [9], though recently several strategies have emerged that require the use of viruses $e x$ vivo to transfect cells that are then re-introduced to the patient. These licensed drugs are summarised in Table 1.

As our knowledge of the molecular regulation of homeostasis has increased, so have the number of "drugable" targets to treat disease. As many of these targets reside within the nucleocytosolic compartment, a way into this compartment for non-membrane permeant molecules is critical. This is especially true for drugs based on nucleic acids which, by default, have no direct way of accessing the nucleocytosolic compartment [4]. Consequently, to be active, nucleic acid 
Table 1. Gene therapeutic drugs licenced for human use.

\begin{tabular}{|c|c|c|c|c|c|}
\hline Brand Name & Drug & Condition & Administration & $\begin{array}{c}\text { Market Authorisation } \\
\text { Holder }\end{array}$ & Reference \\
\hline Strimvelis & $\begin{array}{l}\text { Autologous CD34+ enriched cell } \\
\text { fraction that contains CD34+ cells } \\
\text { transduced with retroviral vector } \\
\text { that encodes for the human ADA } \\
\text { cDNA sequence }\end{array}$ & $\begin{array}{l}\text { Severe Combined Immunodefi- } \\
\text { ciency (SCID) due to Adeno- } \\
\text { sine Deaminase Deficiency } \\
\text { (ADA) }\end{array}$ & Ex Vivo & $\begin{array}{c}\text { Orchard Therapeutics } \\
\text { B.V. }\end{array}$ & [10] \\
\hline Kymriah & $\begin{array}{c}\text { Tisagenlecleucel (chimeric anti- } \\
\text { gen receptor T-cell (CAR-T) } \\
\text { therapy to treat) }\end{array}$ & $\begin{array}{l}\text { Precursor B-Cell Lymphoblas- } \\
\text { tic Leukemia. Lymphoma. } \\
\text { Lymphoma, Large B-Cell, } \\
\text { Diffuse. }\end{array}$ & Ex Vivo & $\begin{array}{l}\text { Novartis Europharm } \\
\text { Limited }\end{array}$ & [11] \\
\hline Glybera & alipogene tiparvovec & Hyperlipoproteinemia Type I & $\begin{array}{l}\text { Intra -muscular } \\
\text { injection }\end{array}$ & $\begin{array}{c}\text { uniQure biopharma } \\
\text { B.V. }\end{array}$ & [81] \\
\hline Gendicin & rAd-p53 & $\begin{array}{l}\text { Head and neck squamous cell } \\
\text { carcinoma }\end{array}$ & $\begin{array}{l}\text { Many including } \\
\text { IP and IV }\end{array}$ & $\begin{array}{c}\text { Shenzhen SiBiono } \\
\text { GeneTech }\end{array}$ & [82] \\
\hline
\end{tabular}

"gene" drugs need to cross several barriers that have evolved to limit both genomic plasticity as well as the expression of exogenous material. Once cellular uptake localises to the ultimately destructive endocytic system, there exist only inefficient and non-specific opportunities for escaping the endocytic compartment $[10,11]$. One example might be the endocytic escape mechanism, which occurs during "leaky" vesicle fusion [10]. Leaky fusion is time-limited, occurring either prior to the enzymatic destruction of the drug, or its exocytosis. Leaky fusion may also be more prevalent in cells kept in exponential growth phase relative to cells undergoing regulated growth in vivo. This may be due to there being more opportunities for fusion in a rapidly expanding population of cells relative to their quiescent in vivo counterparts.

\subsection{Biologics and the Need for Advanced Drug Delivery}

Since the FDA licensing of Vitravene in 1998 [12], there have been a variety of drugs based upon nucleic acids that have been approved in the U.S.A., China and Europe [4]. These are summarised in Tables $1 \& \mathbf{2}$. It is of note that the licensing of Vitravene was followed by its withdrawal from the market in 2001, not because of concerns over safety, but because there was not a high enough demand for the product [13]. It is of note that UniQure has also not renewed the EMA license for the sale of Glybera for similar (i.e. market driven) reasons [14]. The recent FDA licensing of eteplirsen by Sarepta Therapeutics, was also controversial, though this controversy was founded upon the level of dystrophin protein resulting from treatment, rather than the drug's clinical benefit i.e. the activity of the dystrophin produced [15].

To date, all of the antisense drugs that have been licensed have relied on medicinal chemistry to modulate stability rather than using a delivery system to enhance cellular penetration $[4,13]$. There are pipelined, various innovative delivery technologies that are currently under evaluation. One of the more notable is GalNak conjugated siRNA, developed by Alnylam Pharmaceutics [16]. GalNak has been shown to very effectively target siRNA to hepatocytes in vivo. What was not obvious from the literature was the mechanism that GalNak conjugated siRNA utilized to exit the membranebound endocytic system and access the nucleocytosolic compartment after internalisation. There is published evidence that this delivery system increases siRNA efficacy in vivo by up to 5-fold [16]. However, without a mechanism to effect siRNA liberation from the constraints of the endocytic system, it is possible that this system is reliant upon "leaky" vesicle fusion as a means of cytosolic entry. This conundrum is highlighted when the toxicity of non-membrane permeant protein toxins requiring cytosolic translocation is considered. Ricin toxin (RT) depurinates ribosomal RNA at the ricin/sarcin loop, inhibiting protein synthesis. To exert this effect RT a-chain (RTAC) needs to access the cytosol and to then interact with ribosomes [17]. When ricin holotoxin's (i.e. RT a- and b-chain) toxicity was compared with that of RTAC alone, several logs less toxicity were recorded relative to the holotoxin. This was due to the navigation of the endomembrane system afforded by the RT b-chain (RTBC). This example highlights the need for the active navigation of the endomembrane system if the translocation of large membrane non-permeable molecules is required [4, 17].

Beyond the need for modulation of intracellular compartmentalisation, there is also a pressing need to address biologics stability in biological fluid, in vivo half-life and immunogenicity [3]. Conventional solutions to these problems have been addressed using a variety of strategies centring on steric inhibition. Well known examples include PEGylation [18], which requires the covalent attachment of poly(ethyleneglycol) (PEG) to a protein i.e. pegaspargase $\left(\right.$ Oncospar $\left.^{\circledR}\right)$ [19]; the encapsulation of a drug within a liposome such as those used for the formulation of the doxorubicin $\mathrm{HCl}$ liposome injection (Doxil ${ }^{\circledR}$ ) [20]; or the use of an erodible polymer matrix to facilitate the controlled release of the drug goserelin acetate (i.e. Zoladex ${ }^{\circledR}$ ) [21]. PEG is extremely hydrophilic and has been reported to impart "stealth" properties to conjugated proteins, shielding them from both proteases and the immune system [18]. This has the effect of extending attributes like plasma half-life and 
Table 2. Antisense and siRNA drugs licenced for routine clinical use.

\begin{tabular}{|c|c|c|c|c|c|c|}
\hline Brand Name & Drug & Condition & $\begin{array}{l}\text { Mechanism of } \\
\text { Action }\end{array}$ & $\begin{array}{c}\text { Market } \\
\text { Authorisation } \\
\text { Holder }\end{array}$ & Modification & Reference \\
\hline Vitravene & Fomivirsen & $\begin{array}{l}\text { Cytomegalovirus retinitis } \\
\text { (CMV) in immuno- } \\
\text { compromised patients }\end{array}$ & $\begin{array}{l}\text { mRNA destruc- } \\
\text { tion }\end{array}$ & Novartis & Phosphorothioate & [15] \\
\hline Kynamro & Mipomersen & $\begin{array}{l}\text { Homozygous familial } \\
\text { hypercholesterolemia }\end{array}$ & $\begin{array}{l}\text { mRNA destruc- } \\
\text { tion }\end{array}$ & $\begin{array}{l}\text { Genzyme } \\
\text { Corporation }\end{array}$ & $\begin{array}{l}\text { Phosphorothioate ASO } \\
\text { with 2'-O-methoxyethyl- } \\
\text { modified ribose ends }\end{array}$ & [83] \\
\hline Spinraza & Nusinersen & Spinal muscular atrophy & Exon skipping & Biogen & $\begin{array}{c}\text { Phosphorothioate ASO } \\
\text { with 2'-O-methoxyethyl- } \\
\text { modified ribose }\end{array}$ & [84] \\
\hline Eteplirsen & Exondys51 & $\begin{array}{l}\text { Duchenne muscular dys- } \\
\text { trophy }\end{array}$ & Exon skipping & $\begin{array}{l}\text { Sarepta Thera- } \\
\text { peutics Inc. }\end{array}$ & $\begin{array}{l}\text { Uncharged morpholino } \\
\text { oligomers }\end{array}$ & [17] \\
\hline Onpattro & Patisiran & $\begin{array}{l}\text { Hereditary transthyretin- } \\
\text { mediated amyloidosis }\end{array}$ & siRNA & $\begin{array}{l}\text { Alnylam } \\
\text { Pharmaceuti- } \\
\text { cals Inc. }\end{array}$ & $\begin{array}{l}\text { Ribonucleic acid formu- } \\
\text { lated as a lipid complex }\end{array}$ & [85] \\
\hline Tegsedi & Inotersen & $\begin{array}{l}\text { Hereditary transthyretin- } \\
\text { mediated amyloidosis }\end{array}$ & $\begin{array}{l}\text { mRNA destruc- } \\
\text { tion }\end{array}$ & Ionis USA Ltd & $\begin{array}{c}\text { Phosphorothioate ASO } \\
\text { with 2'-O-methoxyethyl- } \\
\text { modified ribose }\end{array}$ & [86] \\
\hline
\end{tabular}

consequently efficacy. A well-cited example of a protein benefiting from "stealth" technology is pegaspargase, which, similar to insulin, has an extracellular target [19]. However, if a (topologically) intracellular target is chosen, another level of delivery is required. Two pertinent examples of protein drugs with intracellular targets are onabotulinumtoxin A $\left(\right.$ Botox $\left.^{\mathbb{B}}\right)$ [21] and denileukin diftitox $\left(\mathrm{Ontak}^{\mathbb{B}}\right)$ [22], both of which utilise highly evolved strategies to overcome subcellular compartmentalisation.

\section{Protein Drugs that Modulate Subcellular Trafficking}

Anabotulinumtoxin A (Botox ${ }^{\circledR}$, Allergan) is the best known of the protein drugs that can achieve third order targeting [21]. Botox ${ }^{\circledR}$ contains serotoxin A from Clostridium botulinum (BoNT). This is marketed under a variety of names, and is used to treat a plethora of conditions. Specific serotypes of botulinum toxin target specific regions of this "soluble N-ethylmaleimide-sensitive factor activating protein receptor (SNARE)-pin" forming complex, cleaving their target proteins and ablating the release of neurotransmitter (i.e. acetylcholine) into the synaptic cleft. Targets include: synaptobrevin, syntaxin, synaptosomal-associated protein of $25 \mathrm{KDa}$ (SNAP-25). SNAP-25 is necessary for neurotransmitter release and is resident upon vesicles (containing neurotransmitter) hemi-fused to the cytosolic leaflet of the presynaptic membrane $[23,24]$. Inactivation of this complex causes flaccid paralysis of muscles, which can be fatal [23]. In order to interact with this family of SNARE related proteins, the botulinum toxins require access to the cytosol, which in turn requires it to translocate out of the endomembrane system. To this end, the botulinum toxins have evolved to encompass not only the catalytic, SNARE interacting lethal domains of the light (L) subunit, but also a membrane interacting and pore forming heavy $(\mathrm{H})$ subunit [23]. Membrane association is mediated by an interaction between polysialoganglioside lipids and synaptic membrane protein receptors on presynaptic nerve terminals via the toxin heavy chain " $C$ " domain [23]. This interaction facilitates the internalisation of the heavy and light chains, connected by a disulphide bond. The acidification of endocytic vesicle drives a conformational change in the "HN" domain of the toxin heavy chain, which mediates membrane insertion, oligomerisation and pore formation [23]. The light chain translocates over the "HN" pore and the disulphide bond connecting the heavy and light chains is reduced, liberating the metalloprotease-containing light chain within the cytosol $[23,24]$. This drug represents a market of close to $\$ 2 \mathrm{Bn}$ a year and underscores the market's acceptance of the use of toxins not just as medicines but also for non-life threatening cosmetic applications [21,22].

Denileukin diftitox (Ontak ${ }^{\circledR}$, Eisai Medical Research Inc.) was approved to treat cutaneous T-cell lymphoma by the FDA in 1999 [22]. In 2006 the license was reviewed following several reports of adverse events, and a black box warning describing the possibility of drug-related vision loss was added to the label [25]. Denileukin diftitox was withdrawn from the market in 2014 [25]. The drug contained a recombinant protein derived from both the receptor-binding domain of interleukin-2 (IL-2) and diphtheria toxin (DT) [22, 25]. Given that the IL-2 receptor is overexpressed on the target neoplasic cells, it was strategized that this would drive enough toxin preferentially into this population of cells to produce a therapeutic effect $[22,25]$. The diphtheria toxin portion of this drug has a similar architecture to the Clostridial toxins previously described [22-24]. DT is a virulence factor produced by Corynebacterium diphtheria, and is syn- 
thesized as a single 535 amino acid precursor. This precursor is cleaved to form DT-A and -B chains, linked by two disulfide bonds, with the DT-B chain containing both transmembrane and receptor-binding domains $[22,25]$. The DT-A chain contains the catalytic domain responsible for inducing cell death. The wild type DT-B receptor-binding domain interacts with the heparin-binding epidermal growth factor precursor receptor, driving toxin internalization and endosomal translocation. The nucleation of multiple transmembrane domains in response to the acidification of the endosome favors their partitioning into the vesicle-limiting membrane, forming a pore. It is through this pore that the catalytic domain of the DT-A chain translocates into the cytoplasm. Once in the cytosol the DT-A catalytic domain exerts intoxication by inhibiting protein synthesis, which is achieved through the deactivation of elongation factor (EF)-2 [22, 25]. Consequently, this drug is an example of a recombinant "synthetic" protein engineered to perform a series of specific tasks. Further, it has been engineered to take advantage of specific protein architecture responsible for both hijacking the endocytic system and mediating endocytic "decompartmentalisation", thus traversing intracellular barriers i.e. membrane.

\subsection{Lysosomal Storage Diseases (LSDs)}

Represent a grey area within the context of large molecules manipulating membrane trafficking processes. From a topological perspective, the lysosome, a depot responsible for enzyme storage (as opposed to catalysis, which occurs within the endolysosome), may be thought of as being outside of the cell [26]. Lysosomal accessibility requires no compartmental barriers to be traversed and is therefore facile. The challenges from a drug delivery perspective lie in keeping delivered material intact and at an appropriate concentration within the endolysosome [27]. The efficiency of endocytic capture should not be overestimated especially if fluid phase capture is to be used. This is exemplified in vitro through the use of endocytic probes labelled with the fluorophore Texas Red. If Texas Red-labelled Bovine Serum Albumin (BSA) is chased into squamous epithelial cells growing on coverslips, a concentration of $5-10 \mathrm{mg} / \mathrm{mL}$ of BSA must be used in order to obtain a robust late endocytic signal after a $4 \mathrm{~h}$ pulse and a $20 \mathrm{~h}$ chase, even in the presence of $200 \mu \mathrm{M}$ leupeptin [28]. In contrast, robust late endocytic labelling using Texas Red-labelled Wheat-Germ Agglutinin (WGA) can be obtained with the same pulse and chase conditions but using a concentration of only $5 \mu \mathrm{g} / \mathrm{ml}$ [29]. This is because the majority of the BSA will enter the cell using (inefficient) fluid phase capture, whereas WGA will bind to $N$-acetyl-D-glucosamine and sialic acid residues, which are abundant membrane constituents, and are subsequently internalised [30, 31].

Access to endolysosomes (also called the late endosome/lysosome hybrid organelle) and lysosomes may be enhanced (relative to fluid phase endocytosis) via an interaction between the deliverable (i.e. a replacement enzyme) and the mannose-6-phosphate receptor (M-6-PR). The M-6-PR has a somewhat circuitous trafficking pathway, cycling between the Golgi and the late endosome directly or via the cell surface. The M-6-PR exists in two forms, the larger $(\sim 300 \mathrm{KDa})$ cation-independent (ci) M-6-PR and the smaller
( $\sim 46 \mathrm{KDa})$ dimeric cation-dependant (cd) M-6-PR ( 46KDa); and both recognise manose-6-phosphate residues present upon glycosylated lysosomal proteins [32]. Although Golgi to late endosome trafficking is mediated by a di-leucine acidic cluster motif, about $10-20 \%$ of the M-6-PR population has been found at the cell surface. This surface localisation of the receptor is believed to provide a scavenger function by retrieving enzymes miss-sorted into the secretory pathway [32]. It is this function that is of interest here as it can be utilised to mediate efficient late endosomal localisation relative to fluid phase capture.

Notable LSDs treated clinically using Enzyme Replacement Therapy (ERT) include Fabry disease [33] and Gaucher disease [34]. Fabry disease is caused by a deficiency in $\alpha$ galactosidase A and can, over a period of many years, lead to the intracellular accumulation of glycosphingolipids [33]. This accumulation of glycosphingolipids can cause renal failure, cardiomyopathy, and cerebrovascular accidents. This condition can usually be treated with agalsidase beta (Fabrazyme $^{\circledR}$ ), a recombinant human $\alpha$-galactosidase A produced in Chinese hamster ovary cells by the Genzyme Corporation [35].

Gaucher disease is caused by a deficiency in glucocerebrosidase (i.e. glucosylceramidase) production [34]. Here mutations render the enzyme sub-optimally active, leading to the accumulation of glucocerebroside, a membrane component of blood cells. This presents clinically as joint pain (often in hips and knees), hepatomegaly, splenomegaly as well as impaired cognition [34]. Treatment options include: imiglucerase for injection (Cerezyme ${ }^{\circledR}$ ), containing recombinant human $\beta$-glucocerebrosidase, made by the Genzyme Corporation, for type 1 Gaucher disease [36]; and taliglucerase alfa (Elelyso ${ }^{\circledR}$ ) made by Pfizer, containing recombinant glucocerebrosidase made using plant cells (i.e. carrot root cell cultures) [37]. In addition to the above, over 50 different conditions have been identified and a detailed description is beyond the scope of this review [38]. From the perspective of this review, the mannosylation of these enzymes is of particular interest as it drives endocytic internalization via the M-6-PR, enabling a more efficient receptor mediated capture of these recombinant molecules, relative to inefficient fluid phase capture of other cargo i.e. ERT [39].

\section{Strategies to Evade Endolysosome Destruction}

Several families of protein toxin have been shown to evade lysosomal destruction via their manipulation of the endomembrane system in order to facilitate access to specific intracellular compartments. Some well-known examples are listed below and include:

RT, a well-characterised binary toxin composed of the catalytically active RTAC and a membrane interacting RTBC held together by a disulphide bond [40]. RTBC is known to bind to both glycoproteins and glycolipids with terminal galactose residues and as a consequence it is taken into the cell by the activities of various coat proteins such as caveolin and clathrin [40].

Golgi translocation occurs from both the rat sarcoma in the brain (rab)5 positive early sorting endosome [40] and the rab11 positive recycling endosome [40]. Translocation from 
endosome to Golgi has been shown to be relatively inefficient, accounting for approximately $5 \%$ of internalised toxin [41] and results in the trafficking of the holotoxin via a rab6a positive route [42]. Further, the requirement of PI3P and hVps34 as well as sorting nexin 2 and 4 have been shown to be critical for RT endosome to Golgi transport [43]. Rab9mediated translocation from the late endosome to the Golgi has been shown to be redundant during ricin intoxication [41]. From the Golgi the holotoxin follows a retrograde route to the ER utilising several possible "carriers" such as calreticulin, which cycles between the ER and the Golgi utilising a COP-1 dependant mechanism [44]. Unlike some of the $\mathrm{AB}_{5}$ toxins detailed subsequently, ricin displayed no obvious ER retrieval motif such as a C-terminal KDEL or RDEL motif [45]. From the lumen of the ER the A chain dislocates from the b-chain and has been documented to translocate through the Sec61p translocon into the cytosol [46], where the RTAC depurinates the ribosomal ricin-sarcin loop, inhibiting elongation factor-1 binding, inhibiting protein synthesis and consequently triggering apoptosis [46].

This rather circuitous route to the cytosol is rather inefficient and the inclusion of a C-terminal KDEL motif in frame with the RTAC significantly increases the molecules' toxicity [45]. Similarly, moving from the reducing environment of the ER lumen to the oxidising environment of the cytosol provides the opportunity for dislocation of the a-chain [46]. From the perspective of drug delivery, it is also worth commenting on the efficiency of the catalytic activity of the ricin a-chain, which has been reported to depurinate ribosomes faster than they can be synthesised. Given the paucity of lysine residues with a-chain, the possibility of ubiquitinylation and destruction by the proteasome can't be discounted. However, this casts a shadow upon the idea that one molecule of cytosolic ricin is enough to kill a cell [47]. That said, the very high activity of the RTAC also hints at the inefficiency of the navigation of the endomembrane system by this toxin.

The $\mathrm{AB}_{5}$ family of toxins includes cholera toxin (CTx), shiga toxin (STx) and pertussis toxins (PTx) [48]. The $\mathrm{AB}_{5}$ toxins are slightly more complex than RT, having a pentomeric assembly of membrane interacting b-chains. This pentomer accommodates the C-terminal region of the catalytically active a-chain via a central aperture. The pentomeric b-chain assembly may be homomeric (CTx and STx) or heteromeric (PTx) [49]. Like RT, $\mathrm{AB}_{5}$ toxins have been shown to traffic from the cell surface with a proportion of internalised toxin being trafficked to the Golgi. From the Golgi there is a further retrograde transport step to the ER before the a-chain dislocates and is able to mediate intoxication via catalytic activity within the cytosol. Once in the ER there are several lines of evidence that point to a variety of different mechanisms being utilised to exit to the cytosol [4, 48].

Anthrax toxin (ATx) has three components, the receptor and membrane interacting protective antigen (PA), lethal factor (LF), which can inactivate mitogen-activated protein kinase (MAPK) kinase, and oedema factor (EF), a $\mathrm{Ca}^{2+}$ and calmodulin dependent adenylate cyclase [48]. In order for the EF and LF to reach their cytosolic targets, intracellular membrane barriers need to be crossed. This is achieved via the interaction of the PA protein with various cellular components. PA is initially synthesised as PA83, an $83 \mathrm{KDa}$ protein. The $20 \mathrm{KDa} \mathrm{N}$-terminal is located downstream of RKKR furin-like protease recognition motif and its hydrolysis triggers PA activation [50]. The dislocation of the PA20 subunit is thought to act as an immunodecoy and may also have toxic properties independent of LF and EF [51]. The activated PA can oligomerise into heptamers, or the less abundant octamers either in solution or at the cell surface after receptor binding [52]. The exact and specific order of events is controversial as one report details a lack of furinlike proteases at the cell surface and another shows that PA63 can oligomerise into annular structures in 50\% serum in the absence of receptors [53]. Further, oligomerisation has been documented in serum after the administration of PA83 in vivo [54]. The three receptors that can recognise, bind and internalise PA oligomers are: (i) Tumour endothelial marker (TEM)8 [55], (also known as anthrax receptor 1), (ii) Capillary morphogenesis gene (CMG)-2, (also referred to as anthrax receptor 2) [56] and (iii) $\beta 1$-integrin [57]. Early endosome acidification drives a conformational change in the PA63n oligomer, extending $2 \beta 2 \mathrm{~s}$ and $2 \beta 3 \mathrm{~s}$ sheets that ultimately form, in the example of a heptamer, a 14-member trans-membrane pore [58]. Following internalisation, the PA receptor is ubiquitinylated and the whole assembly trafficked into microdomains within the early endosome. This membrane is then subject to further deformation and ultimately forms vesicles within a vesicle i.e. intraluminal vesicles (ILVs). This activity is regulated and mediated by the endosomal sorting complexes required for transport (ESCRT) [59]. Once located upon and inserted into the membrane of an ILV, the PA63 oligomer mediates the translocation of cargo in the form of LF or EF [60, 61], which undergoes a molten globular transition [62]. This requires the EF or LF $\mathrm{N}$-terminal to bind to the $\alpha$-clamp [58] on the internal surface of the PA63 oligomer vestibule. Subsequently, further conformational relaxation of the cargo is mediated by the dropping $\mathrm{pH}$ of the endosome in order for "brownian ratcheting" to move the cargo molecule over the $\phi$-clamp and into the lumen of the ILV [50]. An apoptosis linked gene (ALG)2-interacting protein X (ALIX) dependant back-fusion event between the ILV and the limiting membrane of the multivesicular body (MVB) then releases the content of the ILV into the cytosol [60]. It is of note that after translocation into the ILV lumen, the LF and EF are effectively protected from lysosomal hydrolases. Given that the multimeric PA pore is described as a cation selective channel [58] that requires cargo to unfold in order to undergo translocation [62], the observation that supramolecular assemblies containing large anionic components can traverse the PA pore to access the cytosol is of direct interest here [53]. Recently published data describe the cytosolic translocation of both siRNA, antisense oligonucleotides [53], plasmid DNA [62] and plasmid DNA polylysine complexes [63], though it should be noted that plasmid polylysine complexes have been known to rupture endosomal membranes without anthrax toxin components [64]. For this to happen one of several things must be occurring. Firstly, the PA could be weakening, destabilising or bursting the MVB limiting membrane, which would be expected to cause toxicity as lysosomal enzymes would leak into the cytosol [65]. Toxicity was not observed, yet transfection efficiencies as high as those documented 
during nucleofection were reported [62]. Secondly, the supramolecular assembly containing the anionic DNA/ RNA, bound to either a LF truncation (i.e. LFn - also not toxic) fused to a DNA (GAL4) or RNA (Protein Kinase R (PKR)) binding domain is not unfolding and remaining as a complex and the LFn-GAL4/LFn-PKR assembly is translocating across the PA pore intact [62]. This means that PA substrates do not need to unfold to the extent suggested in the literature. Equivalently, a third possibility exists where the LFncomplex is binding to the PA pore and beginning to unfold. This event serves as a "feeder mechanism" that drives the nucleic acid into the pore, suggesting that not only cations but also anions can serve as translocase substrates in this instance. Plasmid translocation is a little harder to reconcile given the conformation and radius of gyration of a covalently closed circular plasmid bound to LFn-GAL4. However, the efficiency with which plasmids were moved into the nucleocytosolic compartment without the aid of polylysine was very low. This paradox is further deepened by the literature describing other proteinaceous LFn fusions that have also been documented as moving through the PA pore. These range from antibody mimetics [66] to the catalytic domains of other toxins and include RTAC [67] and PEA [68]. What is apparent is that this system represents a robust example of domains from several proteins being fused together using recombinant technology to perform useful tasks such as transfection.

Both BoNTs and tetanus toxin (TeNT) bind to the presynaptic membrane of cholinergic terminals with subnanomolar and nanomolar binding affinities [23, 24]. As discussed, BoNT causes flaccid paralysis whereas TeNT causes spastic paralysis and is produced in the wild by Clostridium tetani $[23,24]$. Like BoNT, TeNT exerts its intoxicating effects by blocking neurotransmitter release, in this instance within the spinal chord. TeNT enters the CNS via a synaptic vesicle protein 2 (SV2)-dependent and an SV2independent pathway [23, 24]. Upon endosomal localisation and in response to the drop in endocytic $\mathrm{pH}$, like BoNT, TeNT undergoes a similar conformational change, exposing hydrophobic patches that drive membrane insertion of the heavy-chain. The heavy-chain N-terminus (Hn) mediates membrane translocation and acts after the C-terminus of the heavy-chain has undergone receptor binding driving internalization. TeNT light chain is responsible for the catalytic activity i.e. the hydrolysis vesicle associated membrane protein (VAMP) 7 [23, 24]. Translocation of the light chain occurs after the multimerisation of the Hn domains, forming a membrane ion channel. However, exactly where cytosolic translocation occurs is somewhat more difficult to rationalise as both TEnT and BoNT are known to traffic into small synaptic vesicles which may facilitate neuron-to-neuron toxin transmission i.e. to enter the central nervous system [23, 24].

The cholesterol-dependent cytolysin, streptolysin $\mathrm{O}$ (SLO) represents, along with ATx, one of the few poreforming toxins documented to localise to the membranes of ILVs [59, 60, 61]. Given the mechanism of action of SLO, i.e. like $\alpha$-haemolysin it multimerises, punctures the membrane and allows the unregulated movement (i.e. escape) of cellular components to mediate lysis, this is unexpected. It is possible this is an evolutionary artefact, as unlike ATx PA83 (or 63) there is no apparent functional reason why SLO should translocate to ILVs [69]. This might be an attempt by the cell to partition the toxin into a compartment where it can be safely destroyed without causing harm to the cell. What is interesting is the differential ubiquitinylation of the two ILV translocating toxins. SLO is directly ubiquitinylated [69] whereas ATx is palmitoylated (preventing ubiquitinylation) [61] and it is the ubiquitinylation of the receptor that is responsible for PA ILV translocation. This observation supports the hypothesis that SLO ILV localisation is an attempt by the cell to clear the toxin with minimal damage.

\subsection{Cellular Processes Utilized by Toxins}

The ESCRT machinery consists of 5 complexes [70]. The first, ESCRT 0 contains, in metazoans, hepatocyte growth factor-regulated tyrosine kinase substrate (HRS) and signal transducing adaptor molecule (STAM) proteins. This complex is responsible for recognising ubiquitinylated transmembrane proteins (as opposed to soluble cytosolic proteins), which are then enriched upon the membrane early (i.e. rab5 positive) endosomes. The ESCRT I complex consists of tumour susceptibility gene (TSG) 101, vacuolar protein sorting (Vps) 28, Vps37a, b\&c, and Mvb12a, proteins responsible for cargo selection. The ESCRT II complex (Vps22, Vps25 and Vps36) has been reported to be responsible for membrane deformation during ILV biogenesis and the localisation and enrichment of cargo within proto-ILVs, via interaction with HRS and TSG101 [70].

ESCRT III consists of Vps2a and b, Vps20, Vps24, sucrose non-fermenting protein (Snf) $7 \mathrm{a}, \mathrm{b}$ and c, mVps60, Doa4-independent degradation (Did) $2 a$ and b, Increased Sodium Tolerance (Ist) 1 protein and has been reported to drive vesicle scission. Finally, the Vps4 complex (which consist of Vps4 and Vta1) has been reported to interact with ALIX to regulate ILV recycling and back-fusion events prior to ILV digestion following heterotypic lysosomal fusion [70]. These complexes are collectively responsible for the ubiquitinylation (and de-ubiquitinylation), the enrichment of cargo within specific membrane microdomains, and the subsequent trafficking of that cargo from the plasma membrane into endosomes, and from endosomal limiting membrane into ILVs, which are ultimately destroyed $[70,71]$. From an evolutionary perspective, this process is critical to overcoming the topological problems associated with the attenuation of signalling from activated mitogenic receptors such as the epidermal growth factor receptor [71]. What may be of use to the drug delivery community, is a reported handoff of material i.e. RNA between the RNA-induced silencing (RISC) complex and the ESCRT complex which may be responsible for loading miRNA or mRNA into ILVs prior to their secretion as exosomes [72]. If an entry sequence could be identified and used as a handle it may be used to load over-expressed, synthetic cargo into ILVs or exosomes whilst in transit prior to delivery to the cytosol of the target tissue. However, there remains the problem of exosome target specificity i.e. targeting the correct cell type.

\section{THE PERSONALISATION OF PRECISION MEDI- CINE}

At apogee, the use of patient's own cells to make effective safe medicines is a lofty goal. At perigee, it may be ar- 
gued that this has been achieved using the CAR-T technology [73] previously described. However, a more attainable ambition that still fosters the notion of personalised medicine may be to use patient's cells to deliver or simply hide a drug prior to target assimilation. Over the last 30 years, it has become clear that cells "shed" membrane during their everyday function. This membrane forms extracellular vesicles (EVs), which may be further subdivided into apoptotic bodies' microvesicles and exosomes, a characterisation driven by vesicle size [74].

Exosomes carry the potential for driving a paradigm shift in drug delivery, shielding large therapeutic molecules from the immune system, hydrolytic enzymes, scavenger receptors on cells such as hepatocytes; or the cells of the reticuloendothelial system that could limit PK-PD, as well as provide a way to overcome the topological limitations of the endomembrane system i.e. by facilitating efficient nucleocytosolic delivery [75]. However, many rate limits remain and may be thought of as: 1) Efficient drug loading, 2) Efficient scale-up of production and 3) Regulated cell targeting [75]. Drug loading is still a significant rate limit as methods such as extrusion significantly alter exosome topology during the process [75]. If the topology of proteins necessary for exosome back-fusion after their endocytic uptake by the target cells is incorrect, the subsequent cytosolic delivery of cargo will probably not happen, leading to the destruction of the exosome and its luminal cargo in the endolysosome. Similarly, if the overexpression of cargo or the overexpression of cargo fused to a motif that directs it to an ILV (such as the LAMP/LIMP signalling motif), cellular homeostasis may be altered [76]. It has been reported that neoplasic cells producing exosomes can incorporat neoplasic signalling miRNA or mRNA, which may be detrimental to the recipient cell [77]. Consequently, there is a need for biopsy and to expand healthy cells. If this can be done using the patients' own cells, then there is the potential for personalised medicine. Although targeting is an issue, there may be several potential solutions at hand. The original magic bullet hypothesis did not envisage cell specificity being derived from an advanced drug delivery system but from the drug itself. The use of precision medicines such as siRNA to interact with extra-genomic sequence i.e. virally derived genes such as Ebola Virus RNA-dependent RNA polymerase [78] represents an opportunity for targeting and limiting off-target effects. If the anti-viral siRNA is delivered to an off target i.e. uninfected cell, the result should, in theory, be of no significance. If this target specificity can be combined with exosome specific targeting i.e. as a function of the cell type the exosomes were derived from [79], then further target specificity may be achieved. There may be, hypothetically, a third level of targeting, however this would represent modulating exosome ligand expression to take advantage of receptor expression levels on target cells. Providing this can be done in a way that is not detrimental to the patient (i.e. doesn't stimulate a mitogenic receptor in a cancer cell population) then the delivery of a personalised, precision medicine to a targeted population of the patient's cells may become a reality.

\section{CONCLUSION}

The availability of targets for intervention increases as more is understood about the molecular regulation of cellular physiology and its dysfunction leading to pathology. As the accessibility of these targets to new generations of high molecular weight therapeutics is limited, fresh challenges for drug delivery emerge. Examples include drug stability, drug PK-PD, drug immunogenicity and the ability of the drug to access its target i.e. crossing cellular compartmental barriers. Loading high molecular weight drugs into exosomes represents a strategy that utilises the body's own molecular transport system, hiding precision medicines based upon proteins and nucleic acids from proteases and nucleases as well as the immune system. Should the exosomes be derived from healthy cells from the patient, the paradigm could further change, embracing self/non-self-recognition and the use of a highly personalised delivery technology. However, before this can be achieved, safe and efficient means to harvest, load and target exosomes with these medicines needs to be improved.

\section{LIST OF ABBREVIATIONS}

\begin{tabular}{|c|c|c|}
\hline ATx & $=$ & Anthrax Toxin \\
\hline ALIX & $=$ & $\begin{array}{l}\text { Apoptosis Linked } \\
\text { interacting Protein X }\end{array}$ \\
\hline BoNT & $=$ & Botulinum Toxin \\
\hline$(\mathrm{CMG})-2$ & $=$ & Capillary Morphogenesis Gene \\
\hline CAR-T & $=$ & Chimeric antigen receptor $\mathrm{T}$ - cell \\
\hline CTx & $=$ & Cholera Toxin \\
\hline its & $=$ & Diphtheria Toxin \\
\hline $\mathrm{EF}$ & $=$ & Elongation Factor \\
\hline ESCRT & $=$ & $\begin{array}{l}\text { Endosomal Sorting Complexes Required for } \\
\text { Transport }\end{array}$ \\
\hline ERT & $=$ & Enzyme Replacement Therapy \\
\hline EVs & $=$ & Extracellular Vesicles \\
\hline HRS & $=$ & $\begin{array}{l}\text { Hepatocyte Growth Factor-regulated Tyro- } \\
\text { sine Kinase Substrate }\end{array}$ \\
\hline Ist & $=$ & Increased Sodium Tolerance \\
\hline ILVs & $=$ & Intraluminal Vesicles \\
\hline $\mathrm{LF}$ & $=$ & Lethal Factor \\
\hline LSDs & $=$ & Lysosomal Storage Diseases \\
\hline M-6-PR & $=$ & Mannose-6-phosphate Receptor \\
\hline MVB & $=$ & Multivesicular Body \\
\hline $\mathrm{EF}$ & $=$ & Oedema Factor \\
\hline PTx & $=$ & Pertussis Toxins \\
\hline PEG & $=$ & Poly(ethyleneglycol) \\
\hline PA & $=$ & Protective Antigen \\
\hline PKR & $=$ & Protein Kinase R \\
\hline $\mathrm{rab}$ & $=$ & Rat Sarcoma in the Brain \\
\hline RT & $=$ & Ricin Toxin \\
\hline
\end{tabular}




$\begin{array}{ll}\text { RTAC } & \text { RT a Chain } \\ \text { RISC } & =\text { RNA-induced Silencing } \\ \text { RTBC } & =\text { Shiga Toxin } \\ \text { STx } & =\text { Signal Transducing Adaptor Molecule } \\ \text { STAM } & \text { Soluble N-ethylmaleimide-sensitive Factor } \\ \text { SNARE } & \text { Activating Protein Receptor } \\ \text { SLO } & =\text { Streptolysin O } \\ \text { Snf } & =\text { Synaptosomal-associated protein of } 25 \text { KDa } \\ \text { SNAP-25 } & \text { Synaptic Vesicle Protein } 2 \\ \text { SV2 } & =\text { Tetanus Toxin } \\ \text { TeNT } & =\text { Tumour Endothelial Marker } \\ \text { TEM } & =\text { Tumour Susceptibility Gene } \\ \text { TSG } & =\text { Vacuolar Protein Sorting } \\ \text { Vps } & =\text { Wheat-Germ Agglutinin } \\ \text { VAMP } & \\ \text { WGA } & =\text { Associated Membrane Protein }\end{array}$

\section{CONSENT FOR PUBLICATION}

Not applicable.

\section{CONFLICT OF INTEREST}

SCWR is a Director and serves as the Chief Scientific Officer for Intracellular Delivery Solutions Ltd.

\section{ACKNOWLEDGEMENTS}

SCWR and BKLF would like to thank Greenwich University Enterprises Limited (GUEL) and the Science and Technology Funding Council (STFC) for their support.

\section{REFERENCES}

[1] Walsh G. Post-translational modifications of protein biopharmaceuticals. Drug Discov. Today. 2010, 15(17-18), 773-780.

[2] Rosenfeld P.J.; Schwartz S.D.; Blumenkranz M.S.; Miller J.W.; Haller J.A.; Reimann J.D.; Greene W.L.; Shams N. Maximum tolerated dose of a humanized anti-vascular endothelial growth factor antibody fragment for treating neovascular age-related macular degeneration. Ophthalmology. 2005, 112(6), 1048-1053.

[3] Vaishya R.; Khurana V.; Patel S.; Mitra A.K. Long-term delivery of protein therapeutics. Expert Opin. Drug Deliv., 2015, 12(3), 41540.

[4] Shorter S. A.; Gollings A. S.; Gorringe-Pattrick M.A.M; Coakley J.E.; Dyer P. D. R.; \& Richardson S.C.W. The potential of toxinbased drug delivery systems for enhanced nucleic acid therapeutic delivery. Expert Opin. Drug Deliv., 2017, 14:5, 685-696.

[5] Morris M.C.; Depollier J.; Mery J.; Heitz F.; Divita G. A peptide carrier for the delivery of biologically active proteins into mammalian cells. Nat. Biotechnol. 2001, 19(12), 1173-6.

[6] Kraus A.; Täger J.; Kohler K.; Haerle M.; Werdin F.; Schaller H.E.; Sinis N. Non-viral genetic transfection of rat Schwann cells with FuGENE $\mathrm{HD}^{\circ}$ lipofection and $\mathrm{AMAXA}^{\circ}$ nucleofection is feasible but impairs cell viability. Neuron Glia Biol. 2010, 6(4), 225-30.

[7] Cardarelli F.; Digiacomo L.; Marchini C., Amici A.; Salomone F.; Fiume G.; Rossetta A.; Gratton E.; Pozzi D.; \& Caraccioloa G. The intracellular trafficking mechanism of Lipofectamine-based transfection reagents and its implication for gene delivery. Sci. Rep., 2016, 6, 25879.
[8] Woods G. \& Zito K. Preparation of Gene Gun Bullets and Biolistic Transfection of Neurons in Slice Culture. J. Vis. Exp., 2008, (12), 675.

[9] Nayerossadat N.; Maedeh T. \& Abas Ali P. Viral and nonviral delivery systems for gene delivery. Adv. Biomed. Res., 2012, 1: 27.

[10] Engel A. \& Walter P. Membrane lysis during biological membrane fusion: collateral damage by misregulated fusion machines. J. Cell Biol., 2008, 183(2), 181-186.

[11] Luzio J.P.; Rous B.A.; Bright N.A.; Pryor P.R.; Mullock B.M.; Piper R.C. Lysosome-endosome fusion and lysosome biogenesis. $J$, Cell Sci., 2000, 113(9), 1515-1524.

[12] Geary R.; Henry S.P. \& Grillone L.R.; Fomivirsen: clinical pharmacology and potential drug interactions. Clin. Pharmacokinet., 2002, 41 (4), 255-260.

[13] Stein C. A. \& Castanotto D. FDA-Approved Oligonucleotide Therapies in. Mol. Ther., 2017, 25(5), 1069-1075.

[14] Senior M. After Glybera's withdrawal, what's next for gene therapy? Nature Biotechnology, 2017, 35, 491-492.

[15] Aartsma-Rus A. \& Krieg A. M. FDA Approves Eteplirsen for Duchenne Muscular Dystrophy: The Next Chapter in the Eteplirsen Saga. Nucleic Acid Therapeutics, 2017, 27, (1), 1-3.

[16] Nair J. K.; Willoughby J. L. S.; Chan A.; Charisse K.; Alam M. R.; Wang Q.; Hoekstra M.; Kandasamy P.; Kel'in A. V.; Milstein S.; Taneja N.; O'Shea J.; Shaikh S.; Zhang L.; Sluis R.J.V.D.; Jung M. E.; Akinc A.; Hutabarat R.; Kuchimanchi S.; Fitzgerald K.; Zimmermann T.; Berkel T. J. C. V.; Maier M. A.; Rajeev K. G. \& Manoharan M. (2014) Multivalent N-AcetylgalactosamineConjugated siRNA Localizes in Hepatocytes and Elicits Robust RNAi-Mediated Gene Silencing. J. Am. Chem. Soc., 2014, 136, 16958-16961.

Dyer P.D.R.; Kotha A. K.; Gollings A. S.; Shorter S. A.; Shepherd T. R.; Pettit M. W.; Alexander B. D.; Getti G. T. M.; El-Daher S.; Baillie L.; \& Richardson S. C. W. An in vitro evaluation of epigallocatechin gallate (eGCG) as a biocompatible inhibitor of ricin toxin. Biochim. Biophys. Acta., 2016, 1860(7), 1541-1550.

[18] Khutoryanskiy V.V. Beyond PEGylation: Alternative surfacemodification of nanoparticles with mucus-inert biomaterials. $A d v$. Drug Deliv. Rev., 2018, 124, 140-149.

[19] Rytting M. Peg-asparaginase for acute lymphoblastic leukemia. Expert Opin. Biol. Ther., 2010, 10(5), 833-9.

[20] Bulbake U.; Doppalapudi S.; Kommineni N.; Khan W. Liposomal Formulations in Clinical Use: An Updated Review. Pharmaceutics, 2017, $9(2)$, pii: E12.

[21] Jankovic J. Botulinum toxin: State of the art, Mov, Disord., 2017, $32(8), 1131-1138$.

[22] Baldo B.A. Chimeric fusion proteins used for therapy: indications, mechanisms, and safety. Drug Saf., 2015, 38(5), 455-79.

[23] Pellizzari R.; Rossetto O.; Schiavo G. \& Montecucco C. Tetanus and botulinum neurotoxins: mechanism of action and therapeutic uses. Philos. Trans. R. Soc. Lond. B. Biol. Sci., 1999, 354(1381), 259-268.

[24] Blum F. C.; Chen C.; Kroken A. R.; Barbieri J. T. Tetanus Toxin and Botulinum Toxin A Utilize Unique Mechanisms To Enter Neurons of the Central Nervous System. Infect. Immun., 2012, 80(5), 1662-1669.

[25] Wang Z.; Zheng Q.; Zhang H.; Bronson R.T.; Madsen J.C.; Sachs D.H.; Huang C.A.; Wang Z. Ontak-like human IL-2 fusion toxin. $J$. Immunol. Methods, 2017, 448, 51-58.

[26] Duncan R. \& Richardson S.C. Endocytosis and intracellular trafficking as gateways for nanomedicine delivery: opportunities and challenges. Mol. Pharm., 2012, 9(9), 2380-402.

[27] Li M. Enzyme Replacement Therapy: A Review and Its Role in Treating Lysosomal Storage Diseases. Pediatr. Ann., 2018, 47(5), e191-e197.

[28] Richardson S.C.; Winistorfer S.C.; Poupon V.; Luzio J.P.; Piper R.C. Mammalian late vacuole protein sorting orthologues participate in early endosomal fusion and interact with the cytoskeleton. Mol. Biol. Cell, 2004, 15(3), 1197-210.

[29] Shorter S. A.; Pettit M. W.; Dyer P. D. R.; Youngs E. C.; GorringePattrick A. M. A.; El-Daher S.; \& Richardson S. Green fluorescent protein (GFP): is seeing believing and is that enough? Journal of Drug Targeting, 2017, 9-10, 809-817.

[30] Richardson S.C.; Wallom K. L.; Ferguson E. L.; Deacon S. P.; Davies M. W.; Powell A. J.; Piper R. C.; Duncan R. The use of fluorescence microscopy to define polymer localisation to the late 
endocytic compartments in cells that are targets for drug delivery. J. Control Release, 2008, 127(1),1-11.

[31] Wright C. S. Structural comparison of the two distinct sugar binding sites in wheat germ agglutinin isolectin II. J. Mol. Biol., 1984, 178(1), 91-104.

[32] Nadimpalli S.K.; Amancha P.K. Evolution of mannose 6-phosphate receptors (MPR300 and 46): lysosomal enzyme sorting proteins. Curr. Protein Pept. Sci., 2010, 11(1), 68-90.

[33] Ortiz A.; Germain D.P.; Desnick R.J.; Politei J.; Mauer M.; Burlina A.; Eng C.; Hopkin R. J.; Laney D.; Linhart A.; Waldek S.; Wallace E.; Weidemann F.; Wilcox W.R. Fabry disease revisited: Management and treatment recommendations for adult patients. Mol. Genet. Metab., 2018, 123(4), 416-427.

[34] Chen Y.; Sud N.; Hettinghouse A.; Liu C.J. Molecular regulations and therapeutic targets of Gaucher disease. Cytokine Growth Factor Rev., 2018, 41, 65-74.

[35] Keating G.M. \& Simpson D. Agalsidase Beta: a review of its use in the management of Fabry disease. Drugs, 2007, 67(3), 435-55.

[36] Weinreb N.J. Imiglucerase and its use for the treatment of Gaucher's disease. Expert Opin. Pharmacother., 2008, 9(11), 19872000.

[37] Grabowski G.A.; Golembo M. \& Shaaltiel Y. Taliglucerase alfa: an enzyme replacement therapy using plant cell expression technology. Mol. Genet. Metab., 2014, 112(1), 1-8.

[38] Parenti G.; Andria G. \& Ballabio A. Lysosomal storage diseases: from pathophysiology to therapy. Annu. Rev. Med., 2015, 66, 47186.

[39] Lachmann R.H. Enzyme replacement therapy for lysosomal storage diseases. Curr. Opin. Pediatr., 2011, 23(6), 588-93.

[40] Spooner R.A. \& Lord J.M. Ricin trafficking in cells. Toxins, 2015 7(1), 49-65.

[41] van Deurs B.; Sandvig K.; Petersen O.W.; Olsnes S.; Simons K.; Griffiths G. Estimation of the amount of internalized ricin that reaches the trans-Golgi network. J. Cell Biol., 1988, 106(2), 25367.

[42] Utskarpen A.; Slagsvold H.H.; Iversen T.G.; Wälchli S. \& Sandvig $\mathrm{K}$. Transport of ricin from endosomes to the Golgi apparatus is regulated by Rab6A and Rab6A'. Traffic, 2006, 7(6), 663-72.

[43] Skånland S.S.; Wälchli S.; Utskarpen A.; Wandinger-Ness A. \& Sandvig K. Phosphoinositide-regulated retrograde transport of ricin: crosstalk between hVps34 and sorting nexins. Traffic, 2007, 8(3), 297-309.

[44] Day P.J.; Owens S.R.; Wesche J.; Olsnes S.; Roberts L.M. \& Lord J.M. An interaction between ricin and calreticulin that may have implications for toxin trafficking. J. Biol. Chem., 2001, 276(10), 7202-8.

[45] Wales R.; Roberts L.M.; Lord J.M. Addition of an endoplasmic reticulum retrieval sequence to ricin A chain significantly increases its cytotoxicity to mammalian cells. J. Biol. Chem., 1983, 268(32), 23986-90.

[46] Simpson J.C.; Roberts L.M.; Römisch K.; Davey J.; Wolf D.H. \& Lord J.M. Ricin A chain utilises the endoplasmic reticulumassociated protein degradation pathway to enter the cytosol of yeast. FEBS Lett., 1999, 459(1), 80-4.

[47] Olsnes, S.; Fernandez-Puentes C.; Carrasco L. \& Vazquez, D. Ribosome inactivation by the toxic lectins abrin and ricin. Kinetics of the enzymic activity of the toxin A-chains. Eur. J. Biochem., 1975, 60, 281-288.

[48] Sandvig K.; Torgersen M. L.; Engedal N.; Skotland T. \& Iversen TG. Protein toxins from plants and bacteria: Probes for intracellular transport and tools in medicine, FEBS Letters, 2010, 584, 26262634.

[49] Carbonetti N.H.; Artamonova G.V.; Andreasen C. \& Bushar N. Pertussis toxin and adenylate cyclase toxin provide a one-two punch for establishment of Bordetella pertussis infection of the respiratory tract. Infect. Immun., 2005, 73(5), 2698-703.

[50] Young J.A. \& Collier R.J. Anthrax toxin: receptor binding, internalization, pore formation, and translocation. Annu. Rev. Biochem., 2007, 76, 243-65.

[51] Hammamieh R.; Ribot W.J.; Abshire T.G.; Jett M. \& Ezzell J. Activity of the Bacillus anthracis $20 \mathrm{kDa}$ protective antigen component. BMC. Infect. Dis., 2008, 8:124.

[52] Kintzer A.F.; Sterling H.J.; Tang I.I.; Williams E.R. \& Krantz B.A. Anthrax toxin receptor drives protective antigen oligomerization and stabilizes the heptameric and octameric oligomer by a similar mechanism. PLoS One. 2010, 5(11): e13888.
[53] Dyer P.D.R.; Shepherd T.R.; Gollings A;S.; Shorter S.A.; Gorringe-Pattrick M.A.M.; Tang C.K.; Cattoz B.N.; Baillie L.; Griffiths P.C. \& Richardson S.C.W. Disarmed anthrax toxin delivers antisense oligonucleotides and siRNA with high efficiency and low toxicity. J. Control Release, 2015, 220(Pt A), 316-328.

[54] Moayeri M.; Wiggins J.F.\& Leppla S.H. Anthrax protective antigen cleavage and clearance from the blood of mice and rats. Infect. Immun., 2007, 75(11), 5175-84.

[55] Bonuccelli G.; Sotgia F.; Frank P.G.; Williams T.M.; de Almeida C.J.; Tanowitz H.B.; Scherer P.E.; Hotchkiss K.A.; Terman B.I.; Rollman B.; Alileche A.; Brojatsch J. \& Lisanti M.P. ATR/TEM8 is highly expressed in epithelial cells lining Bacillus anthracis' three sites of entry: implications for the pathogenesis of anthrax infection. Am. J. Physiol. Cell Physiol., 2005, 288(6), C1402-10.

[56] Liu S.; Crown D.; Miller-Randolph S.; Moayeri M.; Wang H.; Hu H.; Morley T. \& Leppla S.H. Capillary morphogenesis protein-2 is the major receptor mediating lethality of anthrax toxin in vivo. Proc. Natl. Acad. Sci. U S A. 2009, 106(30), 12424-9.

[57] Martchenko M.; Jeong S-Y., \& Cohen S. H. Heterodimeric integrin complexes containing $\beta 1$-integrin promote internalization and lethality of anthrax toxin. Proc. Natl. Acad. Sci. U S A. 2010, 107 (35):15583-15588.

[58] Jiang J.; Pentelute B.L.; Collier R.J. \& Zhou Z.H. Atomic structure of anthrax protective antigen pore elucidates toxin translocation. Nature, 2015, 521(7553), 545-9.

[59] Abrami L.; Leppla S.H. \& van der Goot F.G. Receptor palmitoylation and ubiquitination regulate anthrax toxin endocytosis. J. Cell Biol., 2006, 172(2), 309-20.

[60] Abrami L.; Lindsay M.; Parton R.G.; Leppla S.H. \& van der Goot F.G. Membrane insertion of anthrax protective antigen and cytoplasmic delivery of lethal factor occur at different stages of the endocytic pathway. J. Cell Biol., 2004, 166(5), 645-51.

[61] Krantz B.A.; Trivedi A.D.; Cunningham K.; Christensen K.A. \& Collier R.J. Acid-induced unfolding of the amino-terminal domains of the lethal and edema factors of anthrax toxin. J. Mol. Biol., 2004, 344(3), 739-56.

[62] Dyer P. D. R. Development of a Protein-Based Antisense Delivery Platform Modelled on Anthrax Toxin. PhD thesis, University of Greenwich, London, UK, 2013.

[63] Gaur R.; Gupta P.K.; Goyal A.; Wels W. \& Singh Y. Delivery of nucleic acid into mammalian cells by anthrax toxin. Biochem Biophys Res Commun., 2002, 297(5), 1121-7.

[64] Wu G.Y. \& Wu C.H. Receptor-mediated in vitro gene transformation by a soluble DNA carrier system. J. Biol. Chem., 1987, 262(10), 4429-32.

[65] Erdal H.; Berndtsson M.; Castro J.; Brunk U.; Shoshan M.C. \& Linder S. Induction of lysosomal membrane permeabilization by compounds that activate p53-independent apoptosis. Proc. Natl. Acad. Sci. U S A. 2005, 102(1), 192-7.

[66] Liao X.; Rabideau A.E. \& Pentelute B.L. Delivery of antibody mimics into mammalian cells via anthrax toxin protective antigen. Chembiochem., 2014, 15(16), 2458-66.

[67] Shorter S. A. Biochemical characterisation of the translocation of material through the protective antigen (PA) Pore. PhD thesis, University of Greenwich. London, UK, 2017.

[68] Phillips D.D.; Fattah R.J.; Crown D.; Zhang Y.; Liu S.; Moayeri M.; Fischer E.R.; Hansen B.T.; Ghirlando R.; Nestorovich E.M.; Wein A.N.; Simons L.; Leppla S.H. \& Leysath C.E. Engineering anthrax toxin variants that exclusively form octamers and their application to targeting tumors. J. Biol. Chem., 2013, 288(13), 905865.

[69] Corrotte M.; Fernandes M.C.; Tam C. \& Andrews N.W. Toxin pores endocytosed during plasma membrane repair traffic into the lumen of MVBs for degradation. Traffic, 2012, 13(3), 483-94.

[70] Frankel E.B. \& Audhya A. ESCRT-dependent cargo sorting at multivesicular endosomes. Semin. Cell Dev. Biol., 2018, 74:4-10.

[71] Woodman P. ESCRT proteins, endosome organization and mitogenic receptor down-regulation. Biochem. Soc. Trans., 2009, 37(Pt 1), $146-50$

[72] Janas T.; Janas M.M.; Sapoń K. \& Janas T. Mechanisms of RNA loading into exosomes. FEBS Lett., 2015, 589(13), 1391-8.

[73] Porter D.; Frey N.; Wood P. A.; Weng Y.; \& Grupp S. A. Grading of cytokine release syndrome associated with the CAR T cell therapy tisagenlecleucel. J. Hematol. Oncol., 2018, 11: 35. 
[74] Verderio C.; Gabrielli M. \& Giussani P. Role of sphingolipids in the biogenesis and biological activity of extracellular vesicles. $J$. Lipid Res., 2018, 59(8), 1325-1340.

[75] Vader P.; Mol E.A.; Pasterkamp G. \& Schiffelers R.M. Extracellular vesicles for drug delivery. Adv. Drug Deliv. Rev., 2016, 106(Pt A), $148-156$

[76] Hall J.; Prabhakar S.; Balaj L.; Lai CP.; Cerione R.A. \& Breakefield X.O. Delivery of Therapeutic Proteins via Extracellular Vesicles: Review and Potential Treatments for Parkinson's Disease, Glioma, and Schwannoma. Cell Mol. Neurobiol., 2016, 36(3), 41727.

[77] Dörsam B.; Reiners K.S. \& von Strandmann E.P. Cancer-derived extracellular vesicles: friend and foe of tumour immunosurveillance. Philos. Trans. R. Soc. Lond. B. Biol. Sci., 2018, 373(1737), pii: 20160481.

[78] Martin B.; Canard B. \& Decroly E. Filovirus proteins for antiviral drug discovery: Structure/function bases of the replication cycle. Antiviral Res., 2017, 141:48-61.

[79] Kooijmans S.A.A.; Schiffelers R.M.; Zarovni N. \& Vago R. Modulation of tissue tropism and biological activity of exosomes and other extracellular vesicles: New nanotools for cancer treatment. Pharmacol. Res., 2016, 111, 487-500.

[80] Bryant LM, Christopher DM, Giles AR, Hinderer C, Rodriguez JL, Smith JB, Traxler EA, Tycko J, Wojno AP, Wilson JM. Lessons learned from the clinical development and market authorization of Glybera. Hum Gene Ther Clin Dev. 2013, 24(2): 55-64.
[81] Peng Z. Current status of gendicine in China: recombinant human Ad-p53 agent for treatment of cancers. Hum Gene Ther., 2005, 16(9):1016-27

[82] Monaco L. \& Faccio L. Patient-driven search for rare disease therapies: the Fondazione Telethon success story and the strategy leading to Strimvelis. EMBO Mol. Med., 2017, 9(3), 289-292.

[83] Waldmann E, Vogt A, Crispin A, Altenhofer J, Riks I, Parhofer KG. Effect of mipomersen on LDL-cholesterol in patients with severe LDL-hypercholesterolaemia and atherosclerosis treated by lipoprotein apheresis (The MICA-Study). Atherosclerosis., 2017, 259:20-25

[84] Gidaro T. and Servais L. Nusinersen treatment of spinal muscular atrophy: current knowledge and existing gaps. Dev Med Child Neurol. 2018, doi: $10.1111 /$ dmen.14027.

[85] Wood H. FDA approves patisiran to treat hereditary transthyretin amyloidosis., Nat Rev Neurol. 2018, 14(10):570.

[86] Benson M.D., Waddington-Cruz M., Berk J.L., Polydefkis M., Dyck P.J., Wang A.K., Planté-Bordeneuve V., Barroso F.A., Merlini G., Obici L., Scheinberg M., Brannagan T.H. 3rd, Litchy W.J., Whelan C., Drachman B.M., Adams D., Heitner S.B., Conceição I., Schmidt H.H., Vita G., Campistol J.M., Gamez J., Gorevic P.D., Gane E., Shah A.M., Solomon S.D., Monia B.P., Hughes S.G., Kwoh T.J., McEvoy B.W., Jung S.W., Baker B.F., Ackermann E.J. Gertz M.A., Coelho T. Inotersen Treatment for Patients with Hereditary Transthyretin Amyloidosis. $N$. Engl $J$ Med., 2018, 379(1):22-31. 